\section{6 OPEN ACCESS}

\title{
Disease course and outcome of 15 monocentrically treated natalizumab-associated progressive multifocal leukoencephalopathy patients
}

\author{
Stefanie Dahlhaus, ${ }^{1}$ Robert Hoepner, ${ }_{1}^{1}$ Andrew Chan, ${ }^{1}$ Ingo Kleiter, ${ }^{1}$ Ortwin Adams, ${ }^{2}$ \\ Carsten Lukas, ${ }^{3}$ Kerstin Hellwig, ${ }^{1}$ Ralf Gold ${ }^{1}$
}

\section{- Additional material is published online only. To view please visit the journal online (http://dx.doi.org/10.1136/ jnnp-2013-304897). \\ ${ }^{1}$ Department of Neurology, St. Josef-Hospital, Ruhr University Bochum, Bochum, Germany \\ ${ }^{2}$ Department of Virology, University of Duesseldorf, Duesseldorf, Germany ${ }^{3}$ Department of Radiology, St. Josef-Hospital, Ruhr University Bochum, Bochum, Germany}

\section{Correspondence to} Professor Ralf Gold, Department of Neurology, St. Josef-Hospital, Ruhr University Bochum, Gudrunstr. 56, Bochum 44791, Germany; ralf.gold@rub.de

Received 3 January 2013 Revised 12 March 2013 Accepted 20 March 2013 Published Online First 19 April 2013

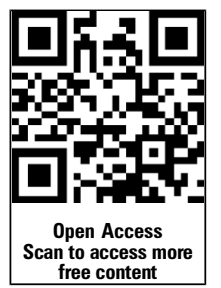

\section{Linked}

http://dx.doi.org/10.1136/ jnnp-2013-305077

To cite: Dahlhaus $S$, Hoepner R, Chan A, et al. I Neurol Neurosurg Psychiatry 2013:84: 1068-1074.

\section{ABSTRACT}

Objective Although the prognosis of natalizumabassociated progressive multifocal leukoencephalopathy (PML) seems to be better than HIV-associated PML, little is known about the long-term functional outcome in multiple sclerosis (MS) patients and the subsequent return of MS disease activity. We evaluated retrospectively 15 patients with natalizumab-associated PML treated at our centre.

Patients and methods Fifteen MS-PML patients (nine women, six men) were referred to us from adjacent local centres. The patients had a median natalizumab exposure of 34 months at PML diagnosis. They received standardised treatment as described in previous work. Expanded Disability Status Scale (EDSS) and Karnofsky score in the year pre-PML, at PML-diagnosis (preimmune reconstitution inflammatory syndrome (IRIS)) and post-PML were determined in 3-6 monthly intervals.

Results The median follow-up of these 15 patients was 21.5 months. None of the 15 patients died. Three patients had a Karnofsky score of 80 or higher, nine patients between 50-70 and three patients of 40 or lower at latest examination. Eight of the 15 patients developed seizures during acute PML phase. Fifty percent of those patients were not seizure-free one year post PML, despite continuation of antiepileptic treatment. The median EDSS in the year pre-PML was 2.5, 4.5 at PML diagnosis, 6.5 post-IRIS and 5.5 at latest examination. CSF became virus-free in eight of the 15 patients after a median time of 4.5 months. In nine patients, disease reappeared after a median time of seven months from PML diagnosis. Conclusions Although the clinical outcome of natalizumab-treated PML patients is much better than in patients with HIV-associated PML, this may be further improved by treatment at reference centres using standardised therapy regimens and transient intensive care if needed. Systematic studies of appropriate MS immunotherapies after PML are critically needed.

\section{INTRODUCTION}

Progressive multifocal leukoencephalopathy (PML) is a rare opportunistic infection of the central nervous system, which usually occurs in the setting of immunosuppression with HIV or cancer patients. ${ }^{1}$ PML was first described in 1958 in a patient with Hodgkin's disease and in two patients with chronic lymphocytic leukaemia. ${ }^{2}$ The assumption of a viral aetiology of PML was made after 1959. ${ }^{3}$ In 1965, intranuclear inclusion bodies in oligodendrocytes were identified by electron microscopy as viral material belonging to the papova group. 5 The causative virus of PML was named JC virus, after the initials of the index patient John Cunningham. ${ }^{6}$

The majority of the population has been exposed to the JC virus-mostly before the age of $15,{ }^{7}$ and about $60 \%$ to $80 \%$ of the adult humans produce persistent antibodies against JCV, which seem to be the most reliable tools to detect latent infection. ${ }^{8}$ In July 2006, the $\alpha 4$-integrin monoclonal antibody natalizumab (Tysabri, BiogenIdec) was reintroduced to the market as a monotherapy for first-line treatment of patients with highly active relapsingremitting multiple sclerosis. ${ }^{9}$ Earlier, the drug had been withdrawn in February 2005 from clinical studies after first approval in 2004 by the US Food and Drug Administration because of three cases of PML in the SENTINEL study ${ }^{10}{ }^{11}$ and in a clinical trial for Crohn's disease. ${ }^{12}$ Approximately 108300 patients have been treated with natalizumab as of September 2012, and 331 cases of natalizumabassociated PML were reported worldwide as of February 2013, with an overall risk of 2,84 cases per 1000 patients (https://www.biogenidec.com). The incidence of PML increases with the duration of treatment. As of February 2013, 70 (22\%) of the worldwide reported natalizumab-associated PML patients have died. In comparison, the one-year survival rate of $\mathrm{HIV}$-associated PML cases after introduction of HAART is about $50 \% .{ }^{13}$ Since the time of our very early report of the successful management of natalizumab-associated PML, ${ }^{14} 15$ patients had been referred to our care, and were subjected to standardised treatment regimens. The goal of this retrospective study was to determine whether a single-centre approach has positive impact on the outcome of these patients, and if suitable follow-up immunotherapies for treatment of multiple sclerosis (MS) can be identified.

\section{METHODS}

We evaluated clinical outcome and functional disability of 15 PML patients-nine women and six men, who were referred to our clinic mostly from the Northwestern part of Germany-using Expanded Disability Status Scale (EDSS) and Karnofsky Performance Scale ${ }^{15}$ in the year pre-PML diagnosis, at PML diagnosis (pre-immune reconstitution inflammatory syndrome IRIS) and post-IRIS in 3-6 monthly intervals, with a median follow-up time of 21.5 months. Ten patients were 
examined and rated by SD. One patient was examined in our neuroimmunological outpatient setting by different physicians in our clinic. We received follow-up information by a local chief of neurology from one patient. The other three patients were examined and rated by IK, AC or KH. All 15 patients were reassessed by SD on the basis of clinical examinations or of oral and written information from other physicians, patients themselves or relatives. All compiled results were also scored by RH. Both neurologists are certificated EDSS-rater (C-Level) (http://www. neurostatus.net). Mild disability was defined by Karnofsky scores of 80 or higher, moderate disability by Karnofsky scores of $50-70$ and severe disability by Karnofsky scores of 40 or lower. The retrospective analysis of patient data has been approved by the Bochum ethics committee 4566-13.

The cerebrospinal fluid (CSF) and serum analyses for JCV-DNA of 14 patients were performed at the Institute for Virology, University Duesseldorf, which is one of Germany's reference centres. Frozen pre-PML sera were retrieved from our own nationwide test centre for anti-natalizumab antibodies. ${ }^{16}$

For MRI, routine scans at 1.5 Tesla machines, a standard protocol for MS (T1-weighted scans with and without Gadolinium (GD) contrast, T2-weighted scans and fluid inversion recovery (FLAIR) images) were used and scans were evaluated by a single neuroradiologist (CL). We decided to perform a brain MRI control initially every 4 weeks, then in $2-3$ months intervals, and in case of clinical worsening.

All 15 patients received plasma exchange (PLEX)/immunoadsorption (IA) at the point of PML diagnosis verified by CSF JCV detection to remove natalizumab and supportive treatment with mefloquine (typically with a loading dose of $250 \mathrm{mg}$ for 3 days and then typically $250 \mathrm{mg}$ once a week) and mirtazapine (usually a starting dose of $30 \mathrm{mg}$ per day, if tolerated, a stepwise increase up to $60 \mathrm{mg}$ per day was made).

The definition of IRIS requires the diagnosis of natalizumab-associated PML and paradox worsening of neurological symptoms following the removal of natalizumab by PLEX or IA. Typically, extension of lesions without contrast enhancement or mass effect on neuroimaging was considered to be due to PML progression. Early-PML-IRIS was defined by the evidence of contrast enhancement at the time of PML diagnosis. In late-PML-IRIS contrast enhancement or worsening of PML lesions were observed. ${ }^{17}$ All patients with IRIS received intravenous high-dose corticosteroids (typically $1 \mathrm{~g}$ per 3-5 days), and in two patients, mannitol $(4 \times 125 \mathrm{ml} /$ day $)$ for treatment of cerebral oedema was administered.

Typically, prescribed anticonvulsive medication was levetiracetam $2 \times 500 \mathrm{mg}$ per day with a maximum dose of $2 \times 1500 \mathrm{mg}$. Other antiepileptic drugs used in these patients were lamotrigine, topiramate or lacosamide to adapt antiepileptic treatment after failure of levetiracetam. During the acute phase of seizures, most patients received benzodiazepines such as lorazepam or clonazepam. Transient intensive care or intermediate care management was needed in seven of the 15 patients because of clinical deterioration mostly due to IRIS and/or in case of complex-focal/secondarily generalised seizures.

Clinical relapses post-PML were treated with high-dose methylprednisolone with a typical dose of $1 \mathrm{~g}$ i.v. for 3-5 days. Glatiramer acetate, interferonß-1a, fingolimod or immunoglobulins were used as post-PML immunotherapy.

\section{RESULTS}

Patient demographics and risk factors

In the preceding years, treatment duration for more than 2 years, positive anti-JCV-antibody status and prior use of immunosuppressive agents have been independently identified as risk factors for the development of PML. ${ }^{18}$ Our 15 patients included nine women and six men aged 30-52 years (mean 39.3 years \pm 6.2 ; median 39 years) at PML diagnosis and had a mean MS duration of 12.3 years. All patients were of Caucasian origin. At PML diagnosis natalizumab exposure varied from 13 to 64 months (mean 34.4 months \pm 11.4 ); median 34 months) respectively from 14 to 62 infusions (mean 34.3 infusions \pm 11.1 ; median 32 infusions). All patients had previous immunomodulatory therapy (14 interferons, 1 glatiramer acetate). Six of these received more than one immunomodulatory therapy and two (13.3\%) received immunosuppressive drugs (1 mitoxantrone, 1 azathioprine) (table 1).

Retrospective analysis of frozen and stored pre-PML serum samples showed a positive anti-JCV antibody status in all eight of the 15 patients where samples were available; in seven patients, no pre-PML serum was stored. The EDSS in the year before PML onset ranged from 1.0 to 5.0 (mean 2.6; median 2.5) and the Karnofsky scale from 60 to 100 (mean 83; median 80). The mean and median follow-up times were 19.5 and 21.5 months, respectively. There were no fatal outcomes at the time of this analysis.

\section{Clinical presentation and diagnosis of PML}

In 12 of the 15 patients, new clinical symptoms like depression, cognitive changes, paresis, ataxia or hemianopsia indicated the development of PML. One patient initially presented with two generalised seizures for the first time in her life. ${ }^{19}$ In two of the patients, PML suspicious lesions on routine MRI scans were observed without clinical symptoms, indicating very early stages of PML. Optic neuritis or spinal cord symptoms were not noted as early signs of PML.

The median duration from the first symptoms or MRI suspicious lesions to definite diagnosis of PML (by JCV-DNA detection in CSF analysis) ${ }^{20}$ and removal of natalizumab by PLEX or IA was 30 days (minimum delay 1 day, maximum delay 112 days). In two patients, initially a diagnosis of a new MS relapse was suspected and this delayed proper diagnosis of PML Thus, after typical steroid pulse therapy, these patients unfortunately received another two natalizumab infusions each.

The median CSF viral load at PML diagnosis was 262 copies/ $\mathrm{ml}$. In five of the 15 patients, the initial CSF viral load was below 100 copies/ml, five had a CSF viral load between 100-2000 copies/ml and three had a high viral load over 2000 copies $/ \mathrm{ml}$. In one of the 15 patients, the viral load at PML diagnosis was not quantified, and in another patient with typical clinical symptoms and MRI lesions, JCV-DNA ${ }^{20}$ remained undetectable in CSF analyses. In 11 patients, the viral load increased during the IRIS phase. CSF became virus-free in eight of the 15 patients after a median time of 4.5 months. A brain biopsy was not needed in any of these cases (table 2).

In all 15 patients, new lesions on brain MRI scans were detectable. PML lesions on initial MRI scans were unilobar in four of the 15 patients. Five of the 11 cases with initially multilobar PML lesions later on spread to bihemispheral affliction. Most of the supratentorial PML lesions were located in the frontal or parietal lobe followed by the occipital, and most rarely, temporal lobe. Only one patient presented with an infratentorial (cerebellar) lesion and two patients had both supratentorial and infratentorial lesions at onset of PML. Gadolinium enhancement in these lesions already at PML diagnosis was observed in four patients (table 3).

While none of the patients had seizures before PML diagnosis, eight of the 15 patients (53\%) developed focal, complex- 
Table 1 Baseline demographics

\begin{tabular}{|c|c|c|c|c|c|c|c|c|c|c|c|c|c|c|c|}
\hline Patients & Pat 1 & Pat 2 & Pat 3 & Pat 4 & Pat 5 & Pat 6 & Pat 7 & Pat 8 & Pat 9 & Pat 10 & Pat 11 & Pat 12 & Pat 13 & Pat 14 & Pat 15 \\
\hline Sex $(0=$ male $/ 1=$ female $)$ & 0 & 1 & 0 & 0 & 1 & 1 & 1 & 0 & 1 & 1 & 1 & 1 & 0 & 0 & 1 \\
\hline Age at MS diagnosis (in years) & 20 & 21 & 31 & 23 & 39 & 34 & 21 & 36 & 34 & 31 & 29 & 21 & 30 & 30 & 32 \\
\hline Age at PML diagnosis (in years) & 32 & 32 & 40 & 33 & 46 & 38 & 30 & 52 & 45 & 46 & 34 & 41 & 43 & 36 & 41 \\
\hline MS duration (in years) & 15 & 11 & 10 & 11 & 9 & 4 & 12 & 20 & 13 & 16 & 7 & 24 & 14 & 8 & 10 \\
\hline MS duration until escalation natalizumab (in years) & 9 & 5 & 5 & 6 & 4 & 2 & 7 & 15 & 9 & 12 & 3 & 18 & 10 & 4 & 6 \\
\hline Duration natalizumab treatment (in months) & 34 & 64 & 50 & 43 & 31 & 25 & 32 & 13 & 26 & 39 & 25 & 30 & 31 & 37 & 36 \\
\hline Number of natalizumab infusions ( $\mathrm{n}$ ) & 34 & 62 & 51 & 40 & 30 & 27 & 30 & 14 & 24 & 40 & 26 & 29 & 32 & 38 & 37 \\
\hline Prior immunosuppressive agents $(0=n / 1=y)$ & 0 & 0 & 0 & 0 & 0 & 0 & 1 & 1 & 0 & 0 & 0 & 0 & 0 & 0 & 0 \\
\hline Azathioprine $(0=\mathrm{n} / 1=\mathrm{y})$ & 0 & 0 & 0 & 0 & 0 & 0 & 0 & 1 & 0 & 0 & 0 & 0 & 0 & 0 & 0 \\
\hline Mitoxantrone $(0=\mathrm{n} / 1=\mathrm{y}))$ & 0 & 0 & 0 & 0 & 0 & 0 & 1 & 0 & 0 & 0 & 0 & 0 & 0 & 0 & 0 \\
\hline \multicolumn{16}{|l|}{ MS-Therapie prä-PML } \\
\hline Interferon $\beta-1 \mathrm{~b}$ Betaferon $(0=\mathrm{n} / 1=\mathrm{y})$ & 1 & 0 & 1 & 0 & 0 & 0 & 0 & 0 & 0 & 1 & 1 & 0 & 1 & 0 & 1 \\
\hline Interferonß-1a (Rebif) $(0=\mathrm{n} / 1=\mathrm{y})$ & 0 & 1 & 0 & 1 & 1 & 1 & 0 & 1 & 1 & 0 & 0 & 0 & 1 & 0 & 0 \\
\hline Interferonß-1 a (Avonex) $(0=\mathrm{n} / 1=\mathrm{y})$ & 1 & 1 & 0 & 0 & 0 & 0 & 0 & 1 & 0 & 0 & 0 & 1 & 0 & 1 & 0 \\
\hline Glatiramer acetate $(0=\mathrm{n} / 1=\mathrm{y})$ & 0 & 1 & 0 & 0 & 0 & 0 & 1 & 0 & 0 & 0 & 0 & 0 & 0 & 1 & 0 \\
\hline Immunglobulines $(0=\mathrm{n} / 1=\mathrm{y})$ & 0 & 0 & 0 & 0 & 0 & 0 & 0 & 0 & 0 & 0 & 0 & 1 & 0 & 0 & 0 \\
\hline Anti-JCV-Ab ( $0=$ neg $/ 1=$ pos $/ 2=$ unknown) & 1 & 1 & 2 & 2 & 2 & 1 & 1 & 2 & 1 & 1 & 2 & 1 & 2 & 2 & 1 \\
\hline
\end{tabular}

MS, multiple sclerosis; n, no; neg, negative, PML, progressive multifocal leukoencephalopathy; pos, positive; $y$, yes.

focal or secondary generalised seizures during acute PML phase (see online supplementary table S1). Despite proper antiepileptic treatment (levetiracetam, lacosamide, lamotrigine or topiramate), four of these eight patients were not seizure-free after 1 year post-PML diagnosis. In summary, half of the 15 patients had seizures during acute PML phase, and half of those developed symptomatic focal epilepsy post-PML.

Specific immunorestorative and antiviral treatment

In all 15 patients, PLEX and/or IA were performed to rapidly remove natalizumab and re-establish an intact immune system. Five patients only received PLEX (5-7 sessions), one patient only was treated with IA (5 sessions) and nine patients with PLEX/IA (4-6 sessions). One patient was treated with 9 cycles of PLEX at an external site as an escalating MS relapse therapy, approximately two months before confirmation of PML diagnosis and after that received two more natalizumab infusions. At Bochum, this patient was treated with five cycles of IA to remove natalizumab at the time of PML diagnosis. On clinical grounds, all 15 patients showed initial improvement or stabilisation in the weeks after removal of natalizumab by PLEX/IA.

Supportive therapy with mefloquine (mostly with a loading of $250 \mathrm{mg}$ for 3 days and then typically $250 \mathrm{mg}$ once a week) and mirtazapine (usually a dose of $45 \mathrm{mg}$ per day) were prescribed for all patients. Both mefloquine, an antimalarial agent, and mirtazapine, a 5-hydroxy 2a (5-HT2a)-receptor inhibitor, had shown in vitro inhibitory effects of virus replication. ${ }^{21}{ }^{22}$ In one patient, the mefloquine had to be stopped because of increasing values of liver enzymes.

\section{Immune reconstitution inflammatory syndrome}

Fourteen patients developed IRIS after a mean time of 32 days after natalizumab removal by PLEX/IA. Four patients developed an early-PML-IRIS and 10 patients a late-PML-IRIS. A clinical deterioration indicated the beginning of the IRIS phase in 13 of the 14 patients. In all 14 cases, growing PML lesions with new or progressive gadolinium enhancement on brain MRI scans were found. An increasing CSF viral load was detected in 11 of the 14 patients. During acute IRIS phase, high-dose i.v.

Table 2 CSF JCV viral load

\begin{tabular}{|c|c|c|c|c|c|c|c|c|c|c|c|c|c|c|c|}
\hline Patients & Pat 1 & Pat 2 & Pat 3 & Pat 4 & Pat 5 & Pat 6 & Pat 7 & Pat 8 & Pat 9 & Pat 10 & Pat 11 & Pat 12 & Pat 13 & Pat 14 & Pat 15 \\
\hline \multicolumn{16}{|c|}{ CSF JCV viral load (number of copies in $\mathrm{n} / \mathrm{ml}$ ) } \\
\hline ....at PML diagnosis (n) & 237 & 1390 & 444 & 16 & 64 & 42 & 7400 & 1400 & 597.857 & 6000 & 37 & 286 & not quantified & 0 & 3 \\
\hline ... at 2nd LP (n) & 2927 & 2300 & 1320 & 45 & 544 & 11 & 255 & 2000 & $>30.000$ & 434.000 & 171 & 1387 & 0 & 0 & 8 \\
\hline ... at 3rd LP (n) & 0 & 2040 & 156 & 200 & 179 & 27 & 3870 & 1800 & 20.055 & 8 & 13 & 169 & 0 & 0 & 0 \\
\hline ... at 4th LP (n) & & 658 & & 22 & 29 & & 1825 & 4000 & 3840 & 0 & 5 & 13 & & & 19 \\
\hline ....at 5th LP (n) & & 47 & & 0 & & & 150 & 3000 & 1376 & & 0 & 0 & & & 0 \\
\hline ... at 6th LP (n) & & & & 0 & & & 461 & 0 & & & 0 & & & & 0 \\
\hline ....at 7th LP (n) & & & & & & & 19 & & & & & & & & 0 \\
\hline ... at 8th LP (n) & & & & & & & 3 & & & & & & & & \\
\hline ... at 9th LP (n) & & & & & & & 35 & & & & & & & & \\
\hline $\begin{array}{l}\text { Virus-free after...(in months) } \\
\text { or } 0=\text { not virus-free yet/ } \\
\text { JCV-DNA not detected }\end{array}$ & 6 & 0 & 0 & 3 & 0 & 0 & 0 & 9 & 0 & 9 & 3 & 5 & 1,5 & 0 & 4 \\
\hline
\end{tabular}

$\mathrm{LP}$, lumbar puncture; $n$, number of JCV copies/ml; PML, progressive multifocal leukoencephalopathy. 
Table 3 MRI characteristics

\begin{tabular}{|c|c|c|c|c|c|c|c|c|c|c|c|c|c|c|c|}
\hline \multicolumn{16}{|l|}{ MRI at PML-diagnosis } \\
\hline GD enhancement in PML lesion $(0=n / 1=y)$ & 0 & 0 & 0 & 0 & 0 & 0 & 0 & 1 & 0 & 1 & 1 & 1 & 0 & 0 & 0 \\
\hline \multicolumn{16}{|l|}{ Localisation of PML-lesion(s) } \\
\hline Uni-/multilobular ( $0=$ uni $/ 1=$ multi) & 1 & 0 & 1 & 1 & 1 & 1 & 1 & 0 & 1 & 0 & 1 & 1 & 0 & 0 & 1 \\
\hline Uni-/bihemispheral ( $0=$ uni; $1=b i)$ & 0 & 0 & 1 & 0 & 1 & 0 & 1 & 0 & 1 & 0 & 0 & 1 & 0 & 0 & 0 \\
\hline $\begin{array}{l}\text { Left/right hemispheral }(0=1 \mathrm{e} / 1=\mathrm{ri} / 2=\text { both }(\mathrm{ri}>\mathrm{le}) \text {; } \\
3=\text { both }(\mathrm{le}>\mathrm{ri})\end{array}$ & 0 & 1 & 3 & 1 & 2 & 1 & 2 & 1 & 2 & 0 & 0 & 3 & 1 & 0 & 1 \\
\hline Supra-/infratentorial $(0=$ supra $/ 1=$ infra $/ 2=$ both $)$ & 0 & 1 & 0 & 0 & 2 & 0 & 0 & 0 & 2 & 0 & 0 & 0 & 0 & 0 & 0 \\
\hline Frontal $(0=\mathrm{n} / 1=\mathrm{y})$ & 0 & 0 & 1 & 0 & 1 & 1 & 1 & 0 & 1 & 1 & 1 & 1 & 0 & 0 & 0 \\
\hline Temporal $(0=\mathrm{n} / 1=\mathrm{y})$ & 0 & 0 & 1 & 0 & 1 & 0 & 1 & 1 & 1 & 0 & 0 & 0 & 0 & 0 & 0 \\
\hline Parietal $(0=\mathrm{n} / 1=\mathrm{y})$ & 1 & 0 & 0 & 1 & 1 & 1 & 1 & 1 & 1 & 0 & 1 & 0 & 0 & 1 & 0 \\
\hline Occipital $(0=\mathrm{n} / 1=\mathrm{y})$ & 1 & 0 & 0 & 1 & 0 & 0 & 1 & 0 & 0 & 0 & 1 & 0 & 1 & 0 & 1 \\
\hline Diencephal $(0=n ; 1=y)$ & 0 & 0 & 0 & 0 & 0 & 0 & 0 & 1 & 0 & 0 & 0 & 0 & 0 & 0 & 0 \\
\hline Mesencephal $(0=\mathrm{n} ; 1=\mathrm{y})$ & 0 & 0 & 0 & 0 & 0 & 0 & 0 & 0 & 1 & 0 & 0 & 0 & 0 & 0 & 0 \\
\hline Pontine $(0=\mathrm{n} / 1=\mathrm{y})$ & 0 & 0 & 0 & 0 & 1 & 0 & 0 & 0 & 1 & 0 & 0 & 0 & 0 & 0 & 0 \\
\hline Medulla oblongata $(0=\mathrm{n} / 1=\mathrm{y})$ & 0 & 0 & 0 & 0 & 0 & 0 & 0 & 0 & 0 & 0 & 0 & 0 & 0 & 0 & 0 \\
\hline Cerebellar $(0=\mathrm{n} / 1=\mathrm{y})$ & 0 & 1 & 0 & 0 & 1 & 0 & 0 & 0 & 0 & 0 & 0 & 0 & 0 & 0 & 0 \\
\hline Progression of PML-lesion in IRIS -phase $(0=n / 1=y)$ & 1 & 1 & 1 & 1 & 1 & 1 & 1 & 1 & 1 & 1 & 1 & 1 & 1 & 1 & 1 \\
\hline Uni-/bihemispheral extension of PML-lesions ( $0=$ uni $/ 1=b i)$ & 1 & 1 & 1 & 1 & 1 & 1 & 1 & 1 & 1 & 1 & 1 & 1 & 1 & 1 & 1 \\
\hline GD-enhancement in IRIS-phase $(0=n / 1=y)$ & 1 & 1 & 0 & 1 & 1 & 1 & 1 & 1 & 1 & 1 & 1 & 1 & 1 & 1 & 1 \\
\hline
\end{tabular}

2, right more than left; 3, left more than right; both, supra-/and infratentorial; GD, gadolinium; infra, infratentorial; IRIS, immune reconstitution inflammatory syndrome; le, left; multi, multilobular/or -hemispheral; N, no; PML, progressive multifocal leukoencephalopathy; ri, right; supra, supratentorial; uni, unilobular/or -hemispheral; y, yes.

corticosteroids ( $1 \mathrm{~g}$ per $3-5$ days) were administered, and in two patients, mannitol for the treatment of cerebral oedema was initiated.

In a single patient no IRIS occurred similar to the Dutch patient described in the literature. ${ }^{23}$

\section{Clinical outcome}

The median follow-up time was 21.5 months from PML diagnosis. We evaluated clinical status at PML diagnosis (pre-IRIS) and post-IRIS in 3-6 monthly intervals. There were no fatal cases at the time of the analysis. Functional disability was measured by Karnofsky score and EDSS. The median EDSS in the year pre-PML was 2.5, 4.5 at PML diagnosis, 6.5 post-IRIS and 5.5 at the latest examination. At PML diagnosis, two patients (13.3\%) had mild disability, 11 patients $(73.3 \%)$ had moderate disability and two patients (13.3\%) had severe disability. In IRIS phase, clinical status worsened with the transient need for intensive care unit management in two patients. None of the patients had mild disability, eight $(53.3 \%)$ had moderate disability and seven (46.6\%) had severe disability in IRIS or 1-6 months post PML diagnosis. Patients clinically stabilised after about six months post PML diagnosis. At the latest examination, three patients (20\%) had mild disability, nine patients $(60 \%)$ had moderate disability and three patients $(20 \%)$ had severe disability.

\section{MS activity and treatment post PML}

In nine patients, disease activity (clinical relapse/deterioration due to MS and/or GD enhancement and/or typical T2-lession progression in MRI) reappeared after a mean time of 11 months from PML diagnosis. Clinical relapses or clinical deterioration due to MS reoccurred in four patients after a mean time of 15.5 months. MRI (new contrast enhancement due to MS) activity reappeared in seven patients after a mean time of nine months. In three patients, progression of T2-lesions after a mean time of 15 months was also demonstrated (see online supplementary table S2).
Typically immunmodulatory treatment post-PML was started at the point when CSF was proven virus-free. Yet in one patient, MS activity (new contrast enhancement on brain MRI) reappeared early after 7 weeks post-PML diagnosis. Nine weeks later, this patient was started on interferon B-1a after the first clinical relapse occurred. At this time CSF viral load still showed 47 copies $/ \mathrm{ml}$.

Seven patients received glatiramer acetate, one patient interferon $\mathrm{B}-1 \mathrm{a}$, one patient fingolimod and another immunoglobulins as a post-PML MS treatment. One of the patients previously treated with glatiramer acetate had to be escalated to fingolimod. Five patients were stable without continuous immunotherapy (see online supplementary table S3).

\section{Aspects of social life}

Two of the 15 patients had to be housed permanently in a nursing home post PML, three patients receive a daily caretaking service and seven patients only received custodial support from their family. Nine of the 15 patients are now early retired and six of these patients require supervision of a legal guardian.

\section{DISCUSSION}

Our study showed that within a median follow-up time of 21.5 months, 15 monocentrically treated natalizumab-associated PML patients revealed a $100 \%$ survival rate. Although the global survival rate in natalizumab-associated PML is near $80 \%$ (https://www.biogenidec.com), and thus, significantly higher than in HIV-associated PML or in PML of other aetiology, 24-26 it came as a surprise that no fatal cases were observed. As indicated by the final Karnofsky score, we indeed had severely afflicted patients in this cohort, and no bias of only low EDSS at onset of PML. One may speculate that the proper timing of antiepileptic treatment and, if needed, provision of intensive care are key elements for improved outcome.

In natalizumab-associated PML, the following aspects were described to be associated with a better outcome: younger age at PML diagnosis, less disability (lower EDSS scores pre-PML), 
shorter time between symptoms onset and PML diagnosis, more localised MRI lesions and lower JCV load in CSF at PML diagnosis. $^{27}$ These were the predictors of survival and better outcome found in the first 35 postmarketing PML cases. Natalizumab-associated PML patients revealed mild-to-severe levels of disability. If compared to our study, our cohort had a higher proportion of patients in the range of moderate disability with a Karnofsky score between 50 and 70 .

PML may have a 'freezing effect' on reoccurrence of MS activity, which may be explained by the autoptic findings reported by Stüve et al. ${ }^{28}$ Our current data indicate that also in the post-PML setting MS-typical activity on MRI reappears earlier than clinical relapses or clinical deterioration. New contrast enhancement on MRI due to MS was found after a mean time of 9 months post PML, while clinical relapses and T2-lesion progression on MRI were detected after approximately the same time period of 15 to 15.5 months post-PML.

The restart of immunomodulatory therapy post-PML should be considered early when CSF is found free of JCV, at least with the occurrence of new disease activity. The selection of the appropriate post-PML immunomodulatory treatment is an individual decision and depends on clinical conditions and also on the patient's former therapies. Most of our patients were treated with glatiramer acetate post-PML and failed therapy with interferons before escalation of immunotherapy with natalizumab. Of these patients, one later had to be escalated from glatirameracetate to fingolimod and one patient initially received fingolimod as a post PML treatment. At least five patients were stable without continuous immunotherapy. In conclusion, most patients with previously high disease activity are stabilised with baseline therapy or even without immunotherapy after a median follow-up time of almost 2 years post PML-diagnosis. The possible future role of novel oral therapies in the post PML treatment may deserve further consideration.

Eight of the 15 PML patients with seizures in the acute PML phase were not seizure-free over 1 year post PML diagnosis despite appropriate antiepileptic treatment. This is surprising in a disease that predominantly afflicts the white matter. In HIV or other immunosuppressive diseases, IRIS is not known to be as frequent and aggressive as in natalizumab-associated PML. The minor frequency of $18 \%$ seizures in a cohort of not natalizumab-associated PML versus $53 \%$ in our study may support the assumption of IRIS as a higher risk factor. ${ }^{29}$ Thus, involvement of cortical or juxtacortical regions during IRIS may explain the relatively high proportion of patients that needed permanent antiepileptic treatment. Therefore, we recommend the continuation of a long-term antiepileptic treatment for PML patients who had seizures in the acute phase of the disease. It is known that the prescribed supportive treatment with mainly mefloquine and mirtazapine decreases the epileptogenic threshold. Yet some of our patients had suffered from seizures already before mefloquine and mirtazapine were started. We recommend that both supportive drugs be continued until the JCV-PCR of CSF yields negative results, although this is not an evidence-based recommendation.

Our current data suggest that survival of natalizumabassociated PML is a result of (I) increased clinical vigilance leading to early diagnosis, and (II) standardised and consequent treatment of PML and IRIS.

Acknowledgements We thank Dr Wenning, Offenburg for providing follow-up information on our first common PML patient.

Contributors SD, RH, AC, IK, KH and RG took care of the patients. $C L$ and $O A$ contributed to MRI analyses and virological assays. Study design was made by $\mathrm{KH}$ and RG. The draft of the manuscript was written by SD and RG, and all other coauthors contributed to revision of the manuscript.

Competing interests $A C$ received speaker's and consulting honoraria, scientific grant support from Bayer Healthcare, Biogen-Idec, Merck-Serono, Novartis Pharma and Teva Pharma. IK reports receiving travel reimbursements and speaker and consulting honoraria from Bayer Healthcare, Biogen-Idec, Merck Serono, and Novartis as well as research support from Bayer Healthcare, Novartis and Biogen-Idec. OA received speaker's honoraria from Biogen Idec. CL received speaker's honoraria from Biogen Idec, Novartis and Merck Serono. KHK. Hellwig reports research support from Biogen Idec, Bayer Healthcare, Merck Serono,

Sanofi-Aventis and Novartis Pharma as well as speaker honoraria from Biogen Idec, Bayer Healthcare, Merck-Serono, Sanofi-Aventis and Novartis Pharma. RG has received consultation fees and speakers honoraria from BayerSchering, Biogenldec, MerckSerono, Novartis, Sanofi-Aventis and TEVA. He also acknowledges grant support from BayerSchering, Biogenldec, MerckSerono, Sanofi-Aventis and TEVA

Ethics approval Ruhr University Bochum Ethics Committee no. 4566-13.

Provenance and peer review Not commissioned; externally peer reviewed.

Open Access This is an Open Access article distributed in accordance with the Creative Commons Attribution Non Commercial (CC BY-NC 3.0) license, which permits others to distribute, remix, adapt, build upon this work non-commercially, and license their derivative works on different terms, provided the original work is properly cited and the use is non-commercial. See: http://creativecommons.org/licenses/by-nc/3.0/

\section{REFERENCES}

1 Berger JR. Natalizumab and progressive multifocal leukoencephalopathy. Ann Rheum Dis 2006;65:48-53.

2 Astrom KE, Mancall EL, Richardson EP Jr. Progressive multifocal leuko-encephalopathy; a hitherto unrecognized complication of chronic lymphatic leukaemia and Hodgkińs disease. Brain 1958:81:93-111.

3 Cavanagh JB, Greenbaum D, Marshall AH, et al. Cerebral demyelination associated with disorders of the reticuloendothelial system. Lancet 1959;2:524-9.

4 Waksman BH, Adams RD. Infectious leukoencephalitis. A critical comparison of certain experimental and naturally-occurring viral leukoencephalitides with experimental allergic encephalomyelitis. J Neuropathol Exp Neurol 1962;21:491-518.

5 Zu Rhein G, Chou SM. Particles resembling papova viruses in human cerebral demyelinating disease. Science 1965;148:1477-9.

6 Padhett BL, Walker DL, Zu Rhein GM, et al. Cultivation of the papova-like virus from human brain with progressive multifocal leucoencephalopathy. Lancet 1971:1:1257-60.

7 Dalsgaard Hansen NJ, Madsen C, Stenager E. Progressive multifocal leucoencephalopathy. Ital J Neurol Sci 1996;17:393-9.

8 Knowles WA, Pipkin P, Andrews N, et al. Population-based study of antibody to the human polyomaviruses BKV and JCV and the semian polyomavirus SV 40. J Med Virol 2003;71:115-23.

9 Rudick RA, Stuart WH, Calabresi PA, et al.; SENTINEL Investigators. Natalizumab plus Interferon beta-1a for Relapsing Multiple Sclerosis. N Engl J Med 2006;354:911-23.

10 Kleinschmidt-DeMasters BK, Tyler KL. Progressive multifocal leukoencephalopathy complicating treatment with natalizumab and interferon beta-1a for multiple sclerosis. N Engl J Med 2005;353:369-74.

11 Langer-Gould A, Atlas SW, Green AJ, et al. Progressive multifocal leukoencephalopathy in a patient treated with natalizumab. N Eng/ J Med 2005;353:375-81.

12 Van Assche G, Van Ranst M, Sciot R, et al. Progressive multifocal leukoencephalopathy after natalizumab therapy for Crohńs disease. $N$ Engl J Med 2005:353:362-8.

13 Tan CS, Igor J, Koralnik IJ. Progressive multifocal leukoencephalopathy and other disorders caused by JC virus: clinical features and pathogenesis. Lancet Neurol 2010;9:425-37.

14 Wenning W, Haghikia A, Laubenberger J, et al. Treatment of progressive multifocal leukoencephalopathy associated with natalizumab. N Eng/ J Med 2009;361:1075-80.

15 Karnofsky DA, Burchenal JH. The clinical evaluation of chemotherapeutic agents in cancer. New York, USA: Columbia University Press, 1949:196.

16 Trampe AK, Hemmelmann C, Stroet A, et al. Anti-JC virus antibodies in a large German natalizumab-treated multiple sclerosis cohort. Neurology 2012;78:1736-42.

17 Tan IL, McArthur JC, Clifford DB, et al. Immune reconstitution inflammatory syndrome in natalizumab-associated PML. Neurology 2011:77:1061-7.

18 Bloomgreen G, Richman S, Hotermans C, et al. Risk of natalizumab-associated progressive multifocal leukoencephalopathy. N Engl J Med 2012;366:1870-80

19 Schröder A, Lee DH, Hellwig K, et al. Successful management of natalizumab-associated progressive multifocal leukoencephalopathy and immune reconstitution syndrome in a patient with multiple sclerosis. Arch Neurol 2010;67:1391-4

20 Mentzer D, Prestel J, Adams 0, et al. Case definition for progressive multifocal leukoencephalopathy following treatment with monoclonal antibodies. J Neurol Neurosurg Psychiatry 2012;83:927-33. 
21 Brickelmaier M, Lugovskoy A, Kartikeyan R, et al. Identification and characterization of mefloquine efficacy against JC virus in vitro. Antimicrob Agents Chemither 2009:53:1840-9.

22 Elphick GF, Querbes W, Jordan JA, et al. The human polyomavirus, JCV, uses serotonin receptors to infect cells. Science 2004;306:1380-3.

23 Vennegoor A, Wattjes MP, van Munster ET, et al. Indolent course of progressive multifocal leukoencephalopathy during natalizumab treatment in MS. Neurology 2011;75:574-6.

24 Koralnik IJ. New insights into progressive multifocal leukoencephalopathy. Curr Opin Neurol 2004:17:365-70

25 Engsig $\mathrm{FN}$, Hansen $\mathrm{AB}$, Omland $\mathrm{LH}$, et al. Incidence, clinical presentation, and outcome of progressive multifocal leukoencephalopathy in HIV-infected patients during the highly active antiretroviral therapy era: a nationwide cohort study. J Infect Dis 2009;199:77-83.

26 Shitrit D, Lev N, Bar-Gil-Shirit A, et al. Progressive multifocal leukoencephalopathy in transplant recipients. Transpl Int 2005;17:658-65.

27 Vermersch P, Kappos L, Gold R, et al. Clinical outcomes of natalizumabassociated progressive multifocal leukoencephalopathy. Neurology 2011;76:1697-704.

28 Stüve 0 , Marra CM, Jerome KR, et al. Immune surveillance in multiple sclerosis patients treated with natalizumab. Ann Neurol 2006;59:743-7.

29 Lima MA, Drislane FW, Koralnik IJ. Seizures and their outcome in progressive multifocal leukoencephalopathy. Neurology 2006;66:262. 
of the 32 non-collinear diffusion sensitising gradients, we acquired 70 contiguous slices parallel to the anterior commissure-posterior commissure lines. The following imaging parameters were used: acquisition matrix $=96 \times 96$; reconstructed to matrix $=192 \times 192$; field of view $=240 \times 240 \mathrm{~mm}^{2}$; $\mathrm{TR}=10398 \mathrm{~ms}$; TE=72 ms; parallel imaging reduction factor $\left(\right.$ SENSE factor) $=2$; EPI factor $=59 ; \mathrm{b}=1000 \mathrm{~s} / \mathrm{mm}^{2} ; \mathrm{NEX}=1$ and a slice thickness of $2.5 \mathrm{~mm}$. Reconstruction of oculomotor nerves was performed using DTI Studio software and fibres passing through two regions of interest with a fractional anisotropy of $>0.2$ and a tract turning angle of $<60^{\circ}$. For reconstruction of the oculomotor nerve, we used two regions of interest with an option of cut operation on the axial images. The first region of interest was given at the periaqueductal region according to known anatomy. The second region of interest was placed on the oculomotor nerve area (ventral part of the midbrain). ${ }^{12}$

Diffusion tensor tractography (DTT) of the right oculomotor nerve showed a discontinuation in the area where the right nerve exited the midbrain, compared with the left oculomotor nerve of the patient and a normal control subject (figure 1B,C). On the axial colour map of the midbrain, a defect was observed in the anteromedial portion of the right midbrain in front of the discontinued oculomotor nerve. In this patient, the visual dysfunctions of the right eye (ptosis, limitations of eye movement, except for abduction and mydriasis) appeared to be the result of injury of the right oculomotor nerve. This is compatible with the finding of DTT for the right oculomotor nerve. In addition, injury of the right trochlear nerve was clinically suspected; however, we could not confirm this injury because the trochlear nerve cannot be reconstructed on DTT so far. We consider that traumatic axonal injury is the most plausible mechanism for the injury of the right oculomotor nerve. ${ }^{3}$ To the best of our knowledge, although injury of the oculomotor nerve was demonstrated using DTT in one patient with a midbrain infarct, ${ }^{1}$ this is the first study using DTT to demonstrate injury of the oculomotor nerve in a patient with traumatic brain injury. We believe that reconstruction of the oculomotor nerve using DTT would be helpful in detection of injury of the oculomotor nerve.
Hyeok Gyu Kwon, ${ }^{1}$ Min Su Kim, ${ }^{2}$ Seong Ho Kim, ${ }^{2}$ Sung Ho Jang ${ }^{1}$

${ }^{1}$ Department of Physical Medicine and Rehabilitation, College of Medicine, Yeungnam University, Daegu, Republic of Korea

${ }^{2}$ Department of Neurosurgery, College of Medicine, Yeungnam University, Daegu, Republic of Korea

Correspondence to Dr Sung Ho Jang, Department of Physical Medicine and Rehabilitation, College of Medicine, Yeungnam University 317-1, Daemyungdong, Namku, Taegu 705-717, Republic of Korea; strokerehab@hanmail.net

Acknowledgements This work was supported by the DGIST R\&D Programme of the Ministry of Education, Science and Technology of Korea (13-BD-0401).

Contributors HGK: Study concept and design, Acquisition and analysis of data, MSK: Study concept and design, Acquisition and analysis of data, SHK: Acquisition and analysis of data, Drafting of the manuscript, SHJ: Study concept and design, Drafting and critical revision of the manuscript

Funding The DGIST R\&D Programme of the Ministry of Education, Science and Technology of Korea grant number: 13-BD-0401.

Competing interests None.

Patient consent Obtained.

Ethics approval This study was approved by the Institutional Review Board of Yeungnam University Hospital.

Provenance and peer review Not commissioned; externally peer reviewed.

To cite Kwon HG, Kim MS, Kim SH, et al. I Neurol Neurosurg Psychiatry 2013;84:1073-1074.

Received 4 February 2013

Revised 13 March 2013

Accepted 9 April 2013

Published Online First 4 May 2013

J Neurol Neurosurg Psychiatry 2013;84:1073-1074.

doi:10.1136/jnnp-2013-305111

\section{REFERENCES}

1 Yamada K, Shiga K, Kizu O, et al. Oculomotor nerve palsy evaluated by diffusion-tensor tractography. Neuroradiology 2006;48:434-7.

2 Hodaie M, Quan J, Chen DQ. In vivo visualization of cranial nerve pathways in humans using diffusion-based tractography. Neurosurgery 2010;66: 788-95.

3 Wang JY, Bakhadirov K, Devous MD Sr, et al. Diffusion tensor tractography of traumatic diffuse axonal injury. Arch Neurol 2008;65:619-26. 